\title{
Civil-Structural Engineering: Artist to Technician to Scientist
}

\author{
Emin Aktan* \\ Drexel University, USA
}

*Corresponding author: Emin Aktan, Drexel University, USA.

Received Date: June 20, 2019

Published Date: June 26, 2019

\section{Short Communication}

Civil Engineering is the oldest engineering discipline alongside military engineering, given that archeologists found constructed temples 11,000 years old. Ancient Middle Eastern, Chinese, Greek, Roman and various other civilizations in Asia, Africa and the Americas have left us with remarkable constructed systems made from masonry, wood, iron, steel, concrete and prestressed concrete. The first formal school of civil engineering, grounding first military and subsequently civil engineers in theory is Ecole Polytechnique (est. 1794 during the French Revolution and became a military academy under Napoleon in 1804). In the US the Rensselaer Institute awarded the first civil engineering degree in 1835. However, until the late 1940's a large proportion of civil engineers in the US were trained through apprenticeship. The major canal systems in the Northeast (Erie) and Midwest (Ohio), the transcontinental railroad (with its associated bridges and tunnels), dams and flood protection systems along major rivers and remarkable highway bridges and viaducts as well as many turn-ofthe 20th Century buildings were constructed and maintained by civil engineers who did not graduate from a program but learned their art as apprentices to master engineers and architects. After the Second World War, the society started to consider engineering not as art but as applied science and many additional engineering fields such as mechanical, aerospace, electrical, computer, industrial, chemical, material, biomedical and environmental engineering programs started attracting the best and the brightest.

Civil engineering education programs in North America proliferated from less than 50 (land grant institutions established by the 1890 Morrill Act) to over 250 in the $20^{\text {th }}$ Century. Most of these programs offer curricula to train the incumbents for starting as professionals typically focusing on the planning, designing, construction or management of the built environment. Indeed, in the last decades civil engineers constructed remarkable bridges with spans of nearly two kilometers and tall buildings and towers with heights exceeding 820 meters. Further, we cannot help but appreciate and respect the construction of the interstate highway system in the US and a web of high-speed railroads in Europe and Asia as significant accomplishments of the $20^{\text {th }}$ Century. After we entered the new Millennium, however, leading educators in civil and environmental engineering programs recognized that the graduates were falling short of fulfilling the increasing societal expectations from this profession. Today, the society expects civil and environment engineers not only design, construct, operate and manage the built environment, but also to lead in: (a) the stewardship of the natural environment and sustainability; (b) the management and mitigation of multi-hazards risk in urban centers including climate change; (c) the preservation of historic landmarks and infrastructures; and, (d) Managing the utility and performance while efficient and cost-efficient maintenance and renewal of urban infrastructures and the built environment.

In the new Millennium we are discovering that civil engineers need to be far more proactive in urban planning (typically entrusted to planners and urban scientists) and the implementation of landuse and transportation plans; decisions at each and every stage of infrastructures lifecycle; in recognizing continuing urbanization and the complex system- of-systems that govern life in dense urban regions; and especially the intersections, interactions and interdependencies between different infrastructures and the built environment. Most civil engineers are not sufficiently grounded in economics and finance, political and social science, as well as how (federal, state and especially local) public policy impacts the livability, sustainability and resilience of urban societies that are globally interconnected. We are now clear that societal concerns cannot be addressed by fragmented approaches to curricula 
which is unfortunately at the root of the education offered by most of the ABET accredited programs. Only a handful of programs at elite research universities leverage systems engineering as their foundation for a case-and-project based civil-engineering education. It follows that perhaps the most critical challenge for maintaining the relevance of civil engineers is transforming the civil engineering education and professional practice from a divide and conquer approach towards a holistic and integrative one. Unless future civil engineers grasp the interdependent system-of-systems nature of infrastructures, including their intertwined natural, social and engineered elements, it will not be possible to maintain, renew and sustainably operate them in dense urban regions. We cannot expect a healthy and connected society, a vibrant economy and desirable livability, sustainability and resilience at a dense urban region unless civil engineers gain sufficient insight in the complex relationships between each and every element and system within infrastructures. Civil engineers with such insight can and should contribute to the policy, adoption of technology for lifecycle performance and asset management of infrastructures based on quantitative metrics and data. Every forward-thinking Mayor or civic leader should appoint a qualified civil engineer as an advisor on managing the built environment and infrastructures of a City.

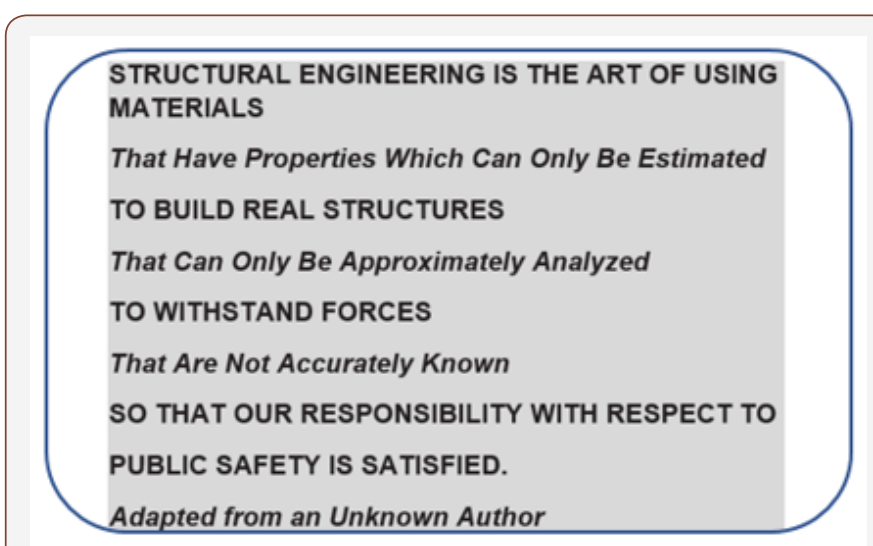

Figure 1: The First Page of Wilson's Book (2002).

\section{The Reality of the Built Environment}

The proliferation of civil engineering programs and civil engineering professionals after the Second World War led to civil engineering becoming a commodity in the new Millennium. Architects such as Pei, Gehry, Calatrava, Foster, Piano, Libeskind, Hadid, Johnson and their civil and structural engineering partners are fast disappearing contemporary giants. Information Technology and software took over structural analysis and design calculations and engineering drawing especially after the 1980's. Most civil engineering education programs started to teach code and software rather than how to observe and learn from the few masters in how they designed and constructed their remarkable products. There is no question that computers and structural analysis and design software brought significant advantages to the few master architects and engineers. However, when these tools were coupled with the proliferation of code-oriented education programs based on empirical information feed - especially reinforced by ABET and the ASCE - the broader civil engineering profession became detached from the reality of how constructed systems are actually loaded and how they respond by distributing their actions and their kinematics, and how changes in weather and soil may affect their actions and their durability. While old masters knew about and accounted for such sources of uncertainty in design, the more recent generations taught to practice engineering by software started believing in the output of the software. The following quote, on the first page of Wilson's (Professor Emeritus, CAL Berkeley) Book (2002), reiterates the significance of learning from masters by apprenticeship and observation.

Today our built environments include many constructed systems, although designed by code, that are not performing in terms of utility and functionality, durability, serviceability, safety and especially resilience. A recent article by Fuller (June 14, 2019 @ NYTimes) discussed the seismic risk posed in San Francisco by Forty high-rise buildings that were constructed between 1960 and 1994 - as the codes of that era were deficient in the welded connections of steel frames observed after recent seismic events. Larger populations of similarly deficient tall buildings exist in South California. Even greater deficiencies with bridges, not just for seismic events but for their daily functions are also well-known as bridge failures in the US indicate a probability of failure of 10-4 as opposed to 10-6 that is expected for buildings. It is imperative for civil engineering education programs to teach as well as all major civil engineering consultants to start measuring the vibrations to extract dynamic properties, strains and drifts for load distribution, and deflections for flexibility of actual as constructed structures and infrastructures. The tools for sensing, imaging and LIDAR scanning are now quite mature, and the civil engineering profession has to adopt measurements as a means of contract delivery by performance-based design and construction. Such as-built measurements to reconcile the actual properties of constructed systems with those envisioned by codes and predicted during design will transform civil engineers from Technicians to Scientists. In addition, by quantitative documentation (birth certificates) of new construction will enable to monitor or occasionally and after each unusual loading incident, evaluate any changes in stiffness and deformations. Given the advent of manufactured construction with the advent of widely used prefabricated members and assemblies, it is time for evaluating constructed systems just like those that are manufactured.

\section{Acknowledgment}

None.

\section{Conflict of Interest}

No conflict of interest. 